\title{
Influence of Silanization Treatment on Thermomechanical Properties of Multiwalled Carbon Nanotubes: Poly(methylmethacrylate) Nanocomposites
}

\author{
Carlos Velasco-Santos, ${ }^{1,2,3}$ Ana Laura Martinez-Hernandez, ${ }^{1,2,3}$ Witold Brostow, ${ }^{3}$ \\ and Victor M. Castaño ${ }^{2}$ \\ ${ }^{1}$ División de Posgrado e Investigación, Instituto Tecnológico de Querétaro, Avenue Tecnológico s/n esquina gral. Mariano Escobedo, \\ Colonia Centro Histórico, 76000 Querétaro, QRO, Mexico \\ ${ }^{2}$ Centro de Física Aplicada y Tecnología Avanzada, Universidad Nacional Autónoma de México, A.P. 1-1010, Santiago de Querétaro, \\ 76000 Querétaro, QRO, Mexico \\ ${ }^{3}$ Laboratory of Advanced Polymers \& Optimized Materials (LAPOM), Department of Materials Science and Engineering, University \\ of North Texas, Denton, TX 76203-5310, USA
}

Correspondence should be addressed to Carlos Velasco-Santos, carlosv@fata.unam.mx

Received 3 May 2011; Revised 26 July 2011; Accepted 30 July 2011

Academic Editor: Gaurav Mago

Copyright (C) 2011 Carlos Velasco-Santos et al. This is an open access article distributed under the Creative Commons Attribution License, which permits unrestricted use, distribution, and reproduction in any medium, provided the original work is properly cited.

\begin{abstract}
Unfunctionalized and silanized multiwalled carbon nanotubes (MWNTs) were incorporated in poly(methylmethacrylate) matrices using in situ polymerization. Polymer-compatible functional groups on carbon nanotube (CNT) surfaces were characterized by infrared spectroscopy. These chemical moieties improve interaction at interfaces, allowing transfer of mechanical load between the matrix and the dispersed phase as reflected in the resulting improved mechanical and thermophysical properties. The composites were characterized by Raman spectroscopy to evaluate molecular level interactions and dynamical mechanical analysis. Composites with silanized CNTs have higher storage modulus $\left(E^{\prime}\right)$ than polymer reinforced with unfunctionalized nanotubes. Considering the average of the samples, only $1 \mathrm{wt} . \%$ of silanized nanotubes provides an increase in $E^{\prime}$ of $165 \%$ at room temperature with respect to polymer matrix, and the increments reached are by a factor of 6.8 and 13.6 over the polymer matrix at $80^{\circ} \mathrm{C}$ and $90^{\circ} \mathrm{C}$, respectively. $1 \mathrm{wt} \%$ of silanized CNTs increases the glass transition temperature of polymer matrix around $30^{\circ} \mathrm{C}$. Microscratch testing results of composites show that unfunctionalized CNTs cause deeper penetration of the indenter than polymer matrix at the same force; however, the composites developed with silanized CNTs present more regular behavior than polymer reinforced with unfunctionalized CNTs.
\end{abstract}

\section{Introduction}

The outstanding properties of carbon nanotubes offer possibilities for developing new strong multifunctional composite materials [1-4]. Several studies have demonstrated the relevant high Young's modulus, stiffness, flexibility, high electrical conductivity, and thermal stability that CNTs posses [5-8]. Research focus to produce polymer composites is directed to taking advantage of these features in maximum level [9-13].

Different reports provide evidence of progress in this area. Depending on the polymer and the processing method used, there are positive effects in the creation of polymeric nanocomposites based on CNTs for mechanical [11-16], electrical [13, 17-20], damping [21], and electroactive properties and artificial muscles $[22,23]$. However, to reach the combination of different properties in one material involves diverse challenges. As discussed by Dzenis [4], uniform distribution of CNTs in the matrix is needed. Moreover, the attention has been paid to mechanical properties than to tribological ones. However, the analysis of tribological properties is needed because the ongoing process in several industries of replacement of metal components by polymeric ones requires polymer-based materials (PBMs) 
with better tribological properties [24]. Recently studies show that the use of CNTs to improve tribology of PBMs turned out to be a two-edged sword; because, while the penetration depths de-crease with increasing concentration of CNTs, the residual depths increase at the same time [16]. Thus, clearly more work also along these lines is needed.

A way to provide uniformity on the distribution of CNTs in a polymeric matrix is functionalization [25-27]. In this paper is presented new evidence related with the efficiency of functionalization to improve compatibility and enhance dispersion and the load transfer of CNTs in polymer nanocomposites. Chemical modification applied to nanotubes is supported in the silanization process, which has been proved as successful method to produce different surface behavior in CNTs. Here we report results for functionalized as well as unfunctionalized carbon nanotube polymer composites. Poly(methyl methacrylate) (PMMA) has been chosen as the matrix because of its wide use.

\section{Experimental}

Methyl methacrylate monomer (MMA) and 3-(trimethoxysilyl)-propyl methacrylate 98\% (3-MAT) were supplied by Aldrich. 2,2'-azoisobutironitrile (AIBN) was donated by GIRSA Company, and arc-discharge MWNTs (ground core materials) were provided by MER Corporation. The core material has around $40 \mathrm{wt} \%$ MWNTs. The product is over $99 \%$ carbon and is produced without catalysts. MWNTs have 8-30 graphene layers and are 6-20 $\mathrm{nm}$ in diameter and 1-5 microns in length.

MWNTs previously purified and oxidized were silanized. Oxidation was achieved with $\mathrm{KMnO}_{4}$ in $\mathrm{H}_{2} \mathrm{SO}_{4}$ medium; this kind of purification is much recognized and produces a high yield and high purity CNTs. Nanotubes obtained by this process have been analyzed by transmission electron microscopy (TEM) and Raman spectroscopy in an earlier paper [28]. Silanization was realized in alcoholic solution; silane was added $1: 1$ in weight with respect to the oxidized CNTs. The mix was refluxed for $3 \mathrm{~h}$, maintaining the temperature around $65-70^{\circ} \mathrm{C}$ and under constant stirring. More details of the reactive concentrations and the procedure to oxidize and silanize CNTs were described in previous publication [28]. Polymer samples and carbon nanotube composites were produced by in situ polymerization using AIBN as the initiator. The AIBN quantity, reaction time, and temperature were controlled in order to achieve narrow molecular weight distributions. The reaction to produce each composite was carried out in a flask using MMA and AIBN in a reflux system. In each type of the samples, unmodified CNTs (uCNTs) and previously silanized CNTs (sCNTs) were added after 30 minutes since the reaction beginning; then sample was maintained at $70^{\circ} \mathrm{C}$ for 2 hours under stirring. The resulting mixture was placed in a glass mold with a latex frame in order to control shrinkage. Finally, the system was controlled at $70^{\circ} \mathrm{C}$ in an oven for 24 hours to achieve complete polymerization. The materials obtained have the thickness of $\approx 1.8 \mathrm{~mm}$. The samples are identified as follows:

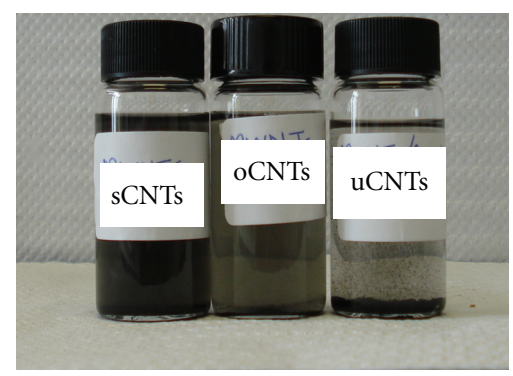

Figure 1: Carbon nanotubes dissolved in acetone: untreated (uCNTs), oxidized (oCNTs), and silanized (sCNTs).

neat PMMA (PMMA), a composite with 1 wt.\% of uCNTs, and a composite with $1 \mathrm{wt} . \%$ of sCNTs.

Two extra samples for each material (PMMA, uCNT composite, and sCNT composite) were prepared to corroborate the nanocomposites and the PMMA behaviour in dynamical mechanical analysis (DMA). The procedure to synthesize the materials was the same described previously.

Infrared analysis was performed using a Vector 33 Bruker spectrophotometer, at 100 scans, with resolution of $1 \mathrm{~cm}^{-1}$. Samples were prepared using $\mathrm{KBr}$ tablets.

For dynamical mechanical analysis, the samples were cut to $6 \mathrm{~mm}$ width and $25 \mathrm{~mm}$ length and tested in a PerkinElmer DMA-7 apparatus, using 3-point bending module at the $1.0 \mathrm{~Hz}$ frequency. Samples were running three times for each material developed.

Raman's spectra of PMMA and composites were obtained in a Micro-Raman Dilor; a $632 \mathrm{~nm}$ laser was used, providing a spectral resolution of $3 \mathrm{~cm}^{-1}$.

Microscratch testing was performed in a machine from CSM, Neuchatel, Switzerland, with their Version 2.3 software. Scratches of $5.00 \mathrm{~mm}$ length were performed using a diamond tip with a $200 \mu \mathrm{m}$ diameter. Samples were tested seven times in different parts of the composite at variable loads from $3.0 \mathrm{~N}$ up to $20.0 \mathrm{~N}$.

\section{Results and Discussion}

3.1. Dispersion in Solvent. Silanization was performed using 3-mercaptopropyl-trimethoxysilane (3-MPT) and 3-(trimethoxysilyl)-propyl methacrylate (3-MAT). CNTs were then dissolved in acetone for 5 minutes using an ultrasonic bath for dispersion and left for further 1 hour without ultrasound. As expected, the dispersion is different, higher for 3MAT than for 3-MTP. Photographs of suspensions obtained using 3-MAT are displayed in Figure 1.

In this figure, it is possible to observe that the darkest suspension corresponds to the system containing sCNTs. These CNTs stay a longer time (several hours) in suspension, while, in the other two systems, precipitation occurs sooner. Even when the acetone is evaporated and sCNTs are washed once more with hot water and acetone in order to eliminate possible remainders of unattached organosilanes, the nanotubes do not lose their dispersion in the solvent. This effect is produced due to the organosilane's R group attached to carbon nanotube surfaces. Organosilanes can be represented as 
b) $\mathrm{R}-\mathrm{Si}\left(\mathrm{OCH}_{3}\right)+3 \mathrm{H}_{2} \mathrm{O} \longrightarrow \mathrm{R}-\mathrm{Si}-\overbrace{\mathrm{OH}}+3 \mathrm{CH}_{3} \mathrm{OH}$

(c)<smiles>[R]CCCOC(=O)C(=C)C</smiles>

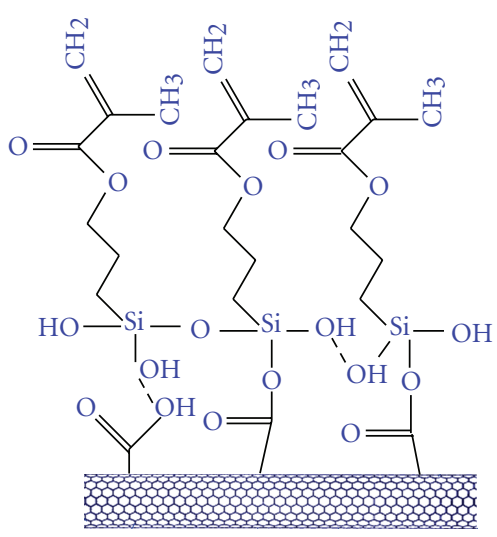

FIGURE 2: Silanization reactions on carbon nanotube surfaces: (a) a general chemical formula of organosilanes, (b) silanization reaction, (c) schematic representation of carbon nanotubes modified with 3-mercaptopropyl-trimethoxysilane.

$\mathrm{R}-\mathrm{Si}-\mathrm{R}_{3}^{\prime}$, where $\mathrm{R}$ is an organofunctional group. The $\mathrm{R}$ group can be selected to be reactive or compatible depending on the organic matrix being used. The $\mathrm{R}^{\prime}$ group is typically trimethoxy $3\left(\mathrm{OCH}_{3}\right)$; silicon-oxygen bonds are formed followed by an easy hydrolysis to trisilanol.

Figure 2 shows a schematic representation of silanization with 3-MAT on carbon nanotube surfaces. The dispersion of sCNTs in the suspension depends on the R group. Our 3-MAT silanization produces good dispersion of CNTs in organic solvents such as acetone or ethanol. The R moiety, in this case the methacrylate chain, changes the behavior of MWNTs when attached to the carbon nanotube surface. When 3-MPT is attached to sCNTs, the thiol group produces lower dispersion in acetone.

3.2. Infrared Spectroscopy. Figure 3 shows the infrared spectra for CNTs, oxidized carbon nanotubes (oCNTs), and sCNTs modified with 3-MAT. Spectrum 3(a) shows two bands in the zone of $\mathrm{A}_{2} \mathrm{u}$ and $\mathrm{E}_{1} \mathrm{u}$ IR phonon modes at $850 \mathrm{~cm}^{-1}$ and $1576 \mathrm{~cm}^{-1}$, which are typical signals of CNTs [29]. In the oCNTs spectrum 3(b) new peaks are seen. Characteristic bands due to oxidation appear; the signals at $1200 \mathrm{~cm}^{-1}$ and $1346 \mathrm{~cm}^{-1}$ are due to $v(\mathrm{C}-\mathrm{O})$ and $\delta(\mathrm{O}-\mathrm{H})$ in plane, respectively; small bands between $1680 \mathrm{~cm}^{-1}$ and $1740 \mathrm{~cm}^{-1}$ correspond to $v(\mathrm{C}=\mathrm{O})[30]$.

In the spectrum of oCNT, carboxylate groups prevail, and only few carboxyl groups are produced. This is seen in low intensities of the bands around $1740 \mathrm{~cm}^{-1}$ and $3320 \mathrm{~cm}^{-1}$ which correspond to $v(\mathrm{C}=\mathrm{O})$ and $v(\mathrm{O}-\mathrm{H})$, typical signals of carboxyl moieties. Other evidence of carboxyl group is a slight increase in $1346 \mathrm{~cm}^{-1} \delta(\mathrm{O}-\mathrm{H})$ and $960 \mathrm{~cm}^{-1} \delta(\mathrm{O}-\mathrm{H})$ related with in-plane and out-of-plane vibrations, respectively [30]. By contrast, a higher intensity is seen in the band around $1495 \mathrm{~cm}^{-1}$, and in the peaks between $1600 \mathrm{~cm}^{-1}$ and

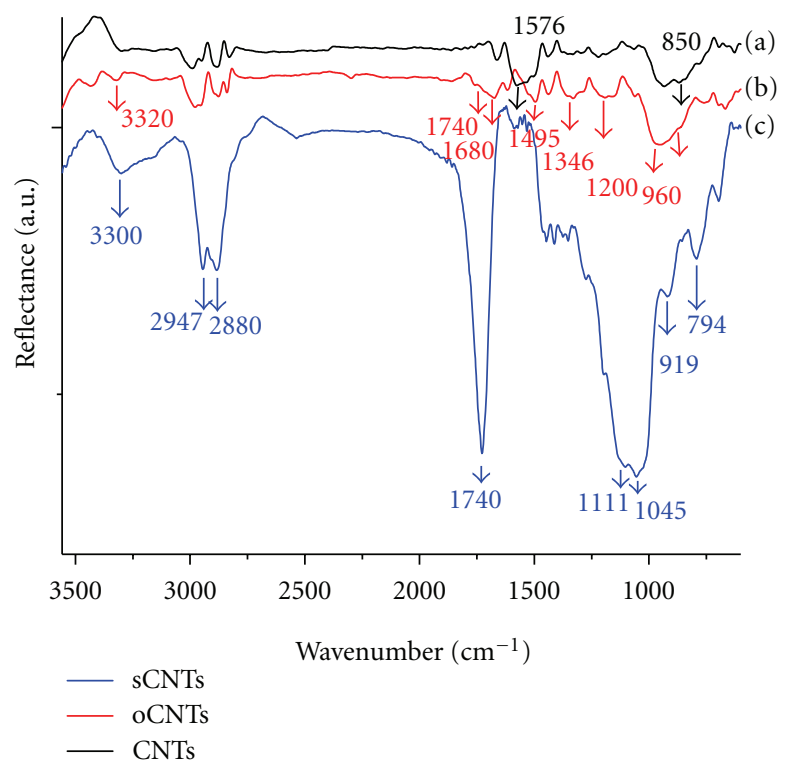

Figure 3: Infrared spectroscopy of CNTs, oCNTs, and sCNTs.

$1680 \mathrm{~cm}^{-1}$ in comparison with the zone above $1700 \mathrm{~cm}^{-1}$, these corroborate that quinone and carboxylate groups exist in these oxidized nanotubes [30-33]. The peak at $1576 \mathrm{~cm}^{-1}$, assigned to $-\mathrm{C}=\mathrm{C}$ in spectrum (a), is notably weaker than that in spectrum (b); this indicates changes in CNT surface due to oxidation [31]; it is known that some damage is produced in CNT walls. In Figure 3(c) we find results of successful silanization process; the bands at $794 \mathrm{~cm}^{-1}$ and $919 \mathrm{~cm}^{-1}$ are typical for $v(\mathrm{Si}-\mathrm{OH})$ and $\delta(\mathrm{OH})$ out of plane. These bands appear when trimethoxy groups are broken in order to form silanol groups. The silanol groups provide 


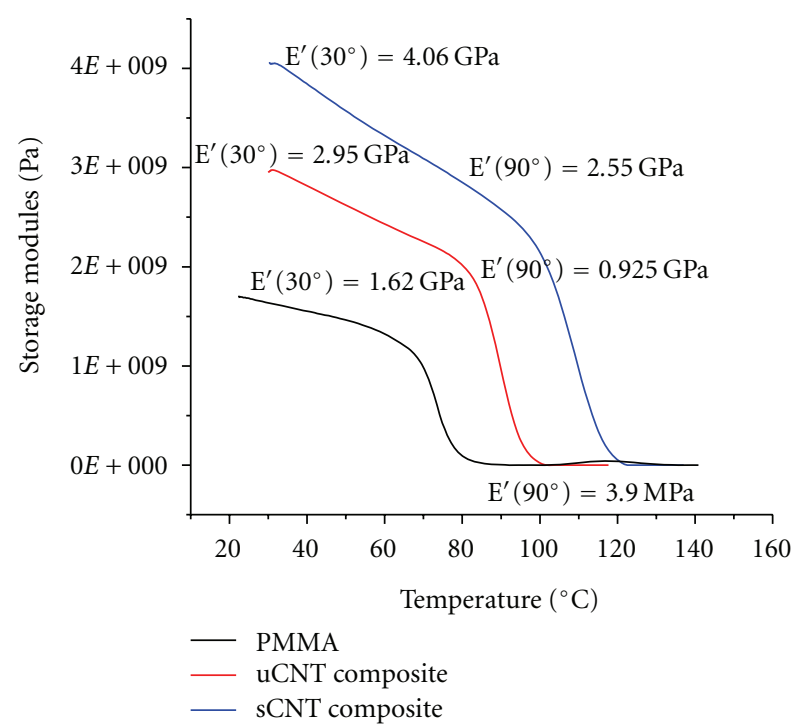

Figure 4: Storage modulus $E^{\prime}$ as a function of temperature for neat PMMA, PMMA with 1.0 wt.\% of unfunctionalized CNTs (uCNTs), and 1.0 wt. $\%$ of CNTs (sCNTs).

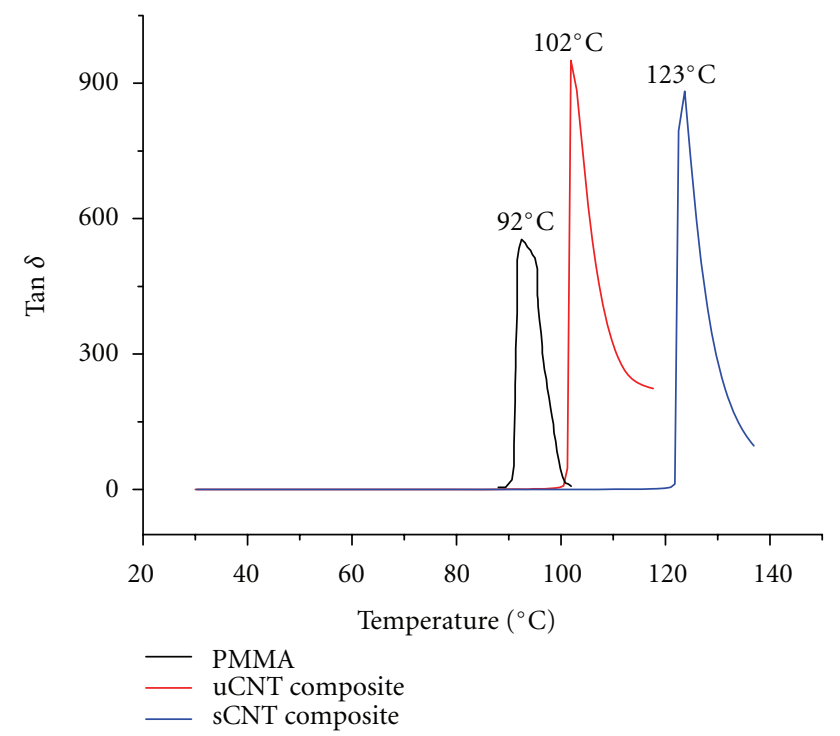

Figure 5: Tan $\delta$ for neat PMMA, PMMA with 1.0 wt.\% of unfunctionalized CNTs (uCNTs), and $1.0 \mathrm{wt} \%$ of CNTs (sCNTs).

interactions between oxygen of carboxylates and hydroxyl moieties of the oxidized nanotubes and the organosilane. In addition spectrum 3(c) does not show bands between $815 \mathrm{~cm}^{-1}$ and $845 \mathrm{~cm}^{-1}$, characteristic signals of nonreacted SiOR groups in organosilane compound $[28,34]$. Also the typical band of methoxy group, around $2850 \mathrm{~cm}^{-1}$, does not appear in this spectrum. The peaks at $1045 \mathrm{~cm}^{-1}$ and $1111 \mathrm{~cm}^{-1}$ are due to Si-O-Si and Si-O-C vibrations $[30,34]$ and correspond to siloxane units formed during silanization process. The high intensity band at $1740 \mathrm{~cm}^{-1}$ becomes stronger due to the ester group $v(\mathrm{C}=\mathrm{O})$ vibration which corresponds to methacrylate moiety. Additionally, in the spectrum appear the peaks at $2880 \mathrm{~cm}^{-1}$ and $2947 \mathrm{~cm}^{-1}$,
$v(\mathrm{C}-\mathrm{H})$ and $v a(\mathrm{C}-\mathrm{H})$, respectively [30], these bands are typical for aliphatic groups and correspond to the propyl chain in this case. Both methacrylate and propyl groups belong to the organosilane compound. The band at $3300 \mathrm{~cm}^{-1}$ typical of $v(\mathrm{O}-\mathrm{H})$ is strong in spectrum $3(\mathrm{c})$ and corresponds to $\mathrm{OH}$ vibration of silanol group. This band is often above $3700 \mathrm{~cm}^{-1}[28,34]$; however, the peak has been located at lower wavenumbers when silanization was performed [33, 34]. It has been suggested that this effect is due to either strong interactions between neighboring silanol groups or between silanol groups and the methacrylate ester moiety of the coupling agent via inter- or intrahydrogen bonding [34]. In our case, the first explanation seems to apply; the strong bands at $1045 \mathrm{~cm}^{-1}$ and $1111 \mathrm{~cm}^{-1}$ shown in Figure 2 corroborate the Si-O-Si interactions. Moreover, no shifts of ester peak typical position $(\mathrm{C}=\mathrm{O})$ are observed in spectrum $3(c)$. Thus, we infer that Si-O-Si interactions occur during silanization.

3.3. Dynamical Mechanical Analysis Results. Figure 4 shows the close average behavior of the storage modulus $\left(E^{\prime}\right)$ as a function of temperature. It is possible to observe in this figure the different behavior of the materials. At $30^{\circ} \mathrm{C}$ neat PMMA shows a value of $E^{\prime}=1.62 \mathrm{GPa}$; PMMA with $1.0 \mathrm{wt} . \%$ of uCNTs shows $E^{\prime}=2.95 \mathrm{GPa}$, while in the composite with sCNT $E^{\prime}$ is presented at $4.06 \mathrm{GPa}$. However, at $90^{\circ} \mathrm{C}$ the respective values are $3.90 \mathrm{MPa}, 0.92 \mathrm{GPa}$, and $2.55 \mathrm{GPa}$. These results show a relevant rise in the composites with sCNTs and represent an increment in elastic modulus of $82 \%$ for the composite with untreated CNTs and $150 \%$ for the composite with sCNTs at $30^{\circ} \mathrm{C}$, with respect to polymer matrix (PMMA). At $90^{\circ} \mathrm{C}$, the average behavior in the composites with uCNTs and sCNTs, $E^{\prime}$ is higher more than 7.4- and 13.6-fold, respectively, with respect to PMMA. In addition in the sample with sCNTs, $E^{\prime}\left(30^{\circ} \mathrm{C}\right)$ is higher in $34 \%$ and $E^{\prime}\left(90^{\circ} \mathrm{C}\right)$ in 1.8 -fold with respect to composite which contains unfunctionalized nanotubes.

Three different samples of PMMA and composites reinforced with functionalized and unfunctionalized nanotubes were probed. The materials were synthesized in order to corroborate the behavior of the composites. Polymers reinforced with sCNTs present the same tendency, in as much as $E^{\prime}\left(30^{\circ} \mathrm{C}\right)$ is superior in all composites which contain functionalized nanotubes. Also, uCNTs composites present a storage modulus $E^{\prime}\left(30^{\circ} \mathrm{C}\right)$ higher than PMMA. Thus, even though the storage modulus curves are not uniform in all materials, the tendency is the same and corroborates the efficiency of the functionalization in composite properties. Thus, it is verified that few loads of carbon nanotubes, and even more sCNTs, have important effect in the elastic behavior of these polymer nanocomposites. Table 1 shows storage modulus of the three materials at different temperatures. It is evident that the interaction (analyzed previously by spectroscopy) produced at the interface level by functionalization plays an important role in mechanical properties of these materials.

DMA also provide information about determination of glass transition temperatures $T_{g}$ [35]. Figure 5 shows 
TABLe 1: Results of dynamical mechanical analysis for three different samples of neat PMMA, PMMA with 1.0 wt.\% of unfunctionalized CNTs (u-CNTs) and $1.0 \mathrm{wt} . \%$ of silanized carbon nanotubes, sCNTs.

\begin{tabular}{lccc}
\hline Sample & $E^{\prime}\left(30^{\circ} \mathrm{C}\right)(\mathrm{GPa})$ & $E^{\prime}\left(90^{\circ} \mathrm{C}\right)(\mathrm{GPa})$ & $T_{g}{ }^{\circ} \mathrm{C}(\mathrm{Tan}$ delta maximum $)$ \\
\hline Pmma1 & 1.24 & $3.9 \mathrm{MPa}$ & 92 \\
Pmma2 & 1.49 & $26 \mathrm{MPa}$ & 100 \\
Pmma3 & 1.65 & 0.519 & 101 \\
Pmma (average) & 1.46 & 0.183 & 97 \\
uCNT composite1 & 2.41 & 1.25 & 105 \\
uCNT composite 2 & 2.95 & 0.925 & 102 \\
uCNT composite 3 & 3.30 & 1.94 & 110 \\
uCNT (average) & 2.88 & 1.37 & 105 \\
sCNT composite 1 & 3.60 & 2.06 & 117 \\
sCNT composite 2 & 4.06 & 2.55 & 123 \\
sCNT composite 3 & 4.50 & 2.90 & 126 \\
sCNT (average) & 3.87 & 2.50 & 122 \\
\hline
\end{tabular}

$\tan \delta=E^{\prime \prime} / E^{\prime}$ as a function of temperature, where $E^{\prime \prime}$ is the loss modulus. Taking the $T_{g}$ at the maximum of $\tan \partial$ peak and PMMA as the reference, addition of untreated CNTs increases the $T_{g}$ by $10^{\circ} \mathrm{C}$, while addition of sCNTs results in a $31^{\circ} \mathrm{C}$ increment. Since only $1 \mathrm{wt} . \%$ of CNTs was added, there are clear evidence of strong interactions between PMMA and sCNTs. Figure shows the tangent delta curves closer to the average behavior in all samples; further results pertaining to the thermal behavior of PMMA and composites are shown in Table 1 .

3.4. Raman Spectroscopy. Figures 6(a), 6(b) and 6(c) show Raman spectra in the region from $600 \mathrm{~cm}^{-1}$ to $1500 \mathrm{~cm}^{-1}$, $1650 \mathrm{~cm}^{-1}$ to $1800 \mathrm{~cm}^{-1}$, and from $2500 \mathrm{~cm}^{-1}$ to $3500 \mathrm{~cm}^{-1}$, for neat PMMA, and the composites which contain uCNTs and sCNTs modified with 3-MAT.

The bands situated at $2953 \mathrm{~cm}^{-1} v a(\mathrm{C}-\mathrm{H})$ in Figure 6(c), $1462 \mathrm{~cm}^{-1} \delta(\mathrm{C}-\mathrm{H}), 1330 \mathrm{~cm}^{-1} \delta(\mathrm{C}-\mathrm{H})$ and $982 \mathrm{~cm}^{-1} v(\mathrm{C}-$ C) in Figure 6(a), and the little shoulders located near of these bands $[30,36,37]$ correspond to vibrations of $\mathrm{C}-\mathrm{C}$ and $\mathrm{C}-\mathrm{H}$ bonds in PMMA. The spectrum for the composite with sCNTs shows larger peaks, apparently due to interactions between end moieties in organosilane and the PMMA matrix. The links achieved after polymerization could be $\mathrm{C}-\mathrm{C}$ and $\mathrm{C}-\mathrm{H}$ interactions. It is important to indicate that the mentioned bands increase also in the composite with unfunctionalized CNTs with respect to PMMA. Thus, It is corroborated the interactions between open $\pi$ bonds broken in the polymerization and $\mathrm{C}-\mathrm{H}-\pi$ interactions. Both phenomena have been found in PMMA with unfunctionalized carbon nanotubes in a previous study by our group [26] and other research realized by Baskaran et al. [38]. However, the bands are stronger when CNTs are functionalized. This shows that more interactions are achieved between carbon polymer chains with carbon nanotubes when these are functionalized.

Two bands related with $\mathrm{C}-\mathrm{O}$ vibrations also are found in the IR spectra: in Figure 6(b), the peak at $1737 \mathrm{~cm}^{-1} v(\mathrm{C}=\mathrm{O})$ and in the Figure 6(a) the band localized at $820 \mathrm{~cm}^{-1}$ (combination of $\mathrm{C}-\mathrm{H}$ and $\mathrm{C}-\mathrm{O}-\mathrm{C}$ deformation $[26,36])$. Both peaks correspond to $\mathrm{C}-\mathrm{O}$ vibrations in PMMA; these signals also are stronger for sCTNs system. Thus, moieties in PMMA which contain carbon and oxygen participate in polymernanotube interactions, more so after functionalization.

The last suggestion is corroborated in the Figure 7; the image show a zoomed view of the Figure 6(a). Here the Raman spectra show the region between $1080 \mathrm{~cm}^{-1}$ and $1500 \mathrm{~cm}^{-1}$. Peaks at $1139 \mathrm{~cm}^{-1}$ and $1200 \mathrm{~cm}^{-1}$ which correspond to C-O-C vibrations $[26,38]$ are seen in PMMA and in the composite with unfunctionalized CNTs. These bands are shifted to $1128 \mathrm{~cm}^{-1}$ and $1183 \mathrm{~cm}^{-1}$, respectively in the spectrum of composite with sCNTs; this shift is not seen in the band at $1462 \mathrm{~cm}^{-1}$ used as reference in the spectra. Thus, it is inferred that PMMA's ester groups interact with organosilane's ester groups on the CNT surface, pro-ducing $\mathrm{C}=\mathrm{O} \cdot \mathrm{OCH}_{3}$ and $\mathrm{C}=\mathrm{O} \cdot \mathrm{H}$ interactions that shift the peaks position. Changes in the bands at $1330 \mathrm{~cm}^{-1}$ and $1390 \mathrm{~cm}^{-1}$ are also evident. The former appears only in the composite spectra and is stronger in the sCNT system. A small shoulder at $1390 \mathrm{~cm}^{-1}$ appears only in the PMMA spectrum. Both bands in the overlap region are attributed to $\mathrm{C}-\mathrm{H}$ deformation; the first peak corresponds to $\delta(\mathrm{C}-\mathrm{H}$ methyne), and the second is attributed to deformation of $\mathrm{C}-\mathrm{H}\left(\mathrm{CH}_{3}\right.$ or $\left.\mathrm{CH}_{2}\right)$ in the polymer. In addition, the signal at $1330 \mathrm{~cm}^{-1}$ is found in the neighborhood of the D band region which corresponds to $\mathrm{CNTs}$ and is related to $\mathrm{sp}^{3}$ hybridization. This suggests that $\mathrm{C}-\mathrm{C}$ and $\mathrm{C}-\mathrm{H}$ moieties are produced between $\mathrm{C}=\mathrm{C}$ methacrylate organosilane groups and the $\mathrm{C}=\mathrm{C}$ of the monomer in the polymerization. The results are changes in polymer group vibrations due to the formed links when CNTs, particularly functionalized ones, are incorporated. Also some contribution of D band could have some effect in the peak at $1330 \mathrm{~cm}^{-1}$ in the nanocomposites.

Returning to Figure 6(c), a peak appears from $2600 \mathrm{~cm}^{-1}$ to $2700 \mathrm{~cm}^{-1}$ in the sCNT system spectrum and is associated with $\mathrm{Si}-\mathrm{H}$ bonds found in silanes $[34,39]$. It is possible that some $\mathrm{Si}$. . H links are created between the organosilane and aliphatic polymer groups. We recall here similarity between $\mathrm{C}$ and Si. 


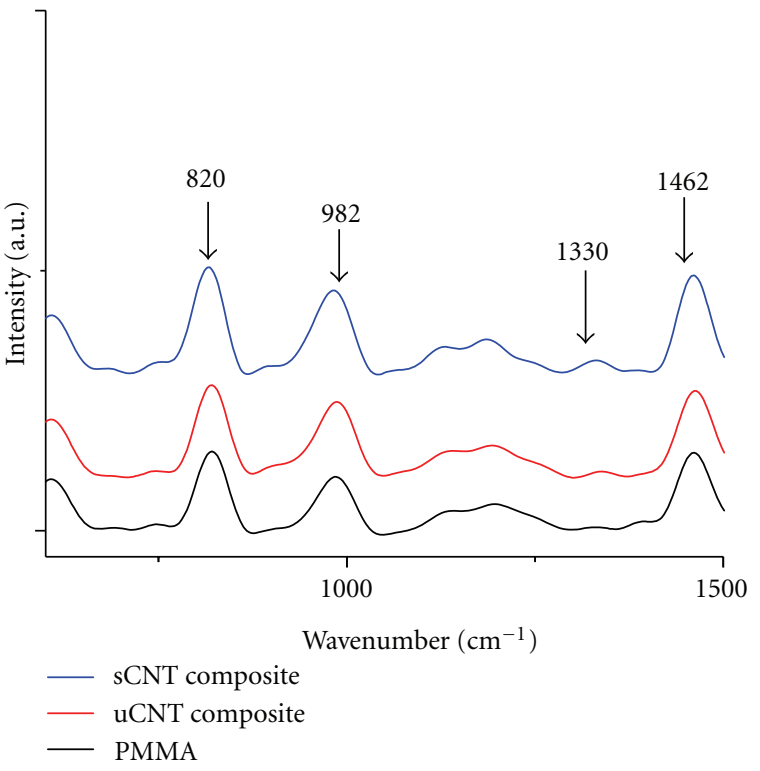

(a)

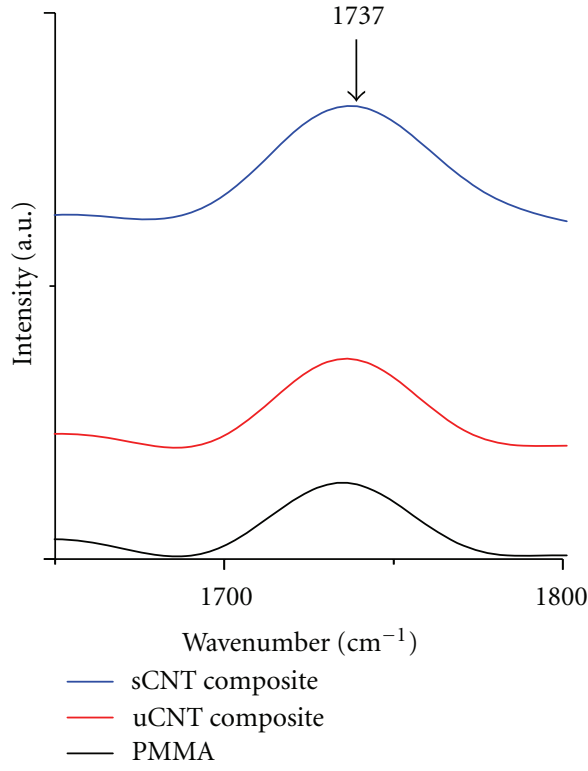

(b)

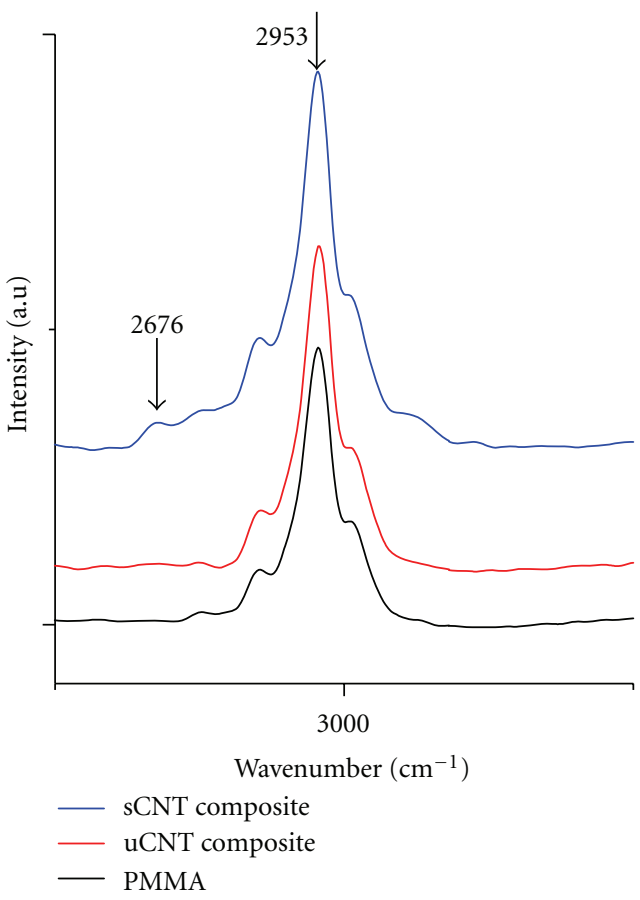

(c)

Figure 6: Raman spectra of PMMA and carbon nanotube polymer nanocomposites (a) from $600 \mathrm{~cm}^{-1}$ to $1500 \mathrm{~cm}^{-1}$, (b) $1650 \mathrm{~cm}^{-1}$ to $1800 \mathrm{~cm}^{-1}$, and (c) from $2500 \mathrm{~cm}^{-1}$ to $3500 \mathrm{~cm}^{-1}$.

3.5. Scratching Behavior. Figure 8 shows penetration depths as a function applied force achieved in PMMA and nanocomposites. Several tests for each kind of material are shown. PMMA samples show regular behavior which is independent of the material section; inasmuch as, the seven analyses present similar penetration depth at the same loads. Thus, PMMA presents homogenous behavior that indicates similar features in any point of its surface. sCNT composite present two zones; in the region from $7.5 \mathrm{~N}$ to $9 \mathrm{~N}$, the majority of the determinations in sCNT composite present better resistance to be penetrated with respect to PMMA; however, in the zone above $9 \mathrm{~N}$, the majority of these samples show lower resistance to the penetration than PMMA. Nevertheless, the largest part of the analysis realized in sCNT composite presents better tribological properties than uCNT composite. Therefore, although a small quantity of sCNTs is incorporated in polymer; better wear resistance is presented at low load with respect to polymer matrix. 


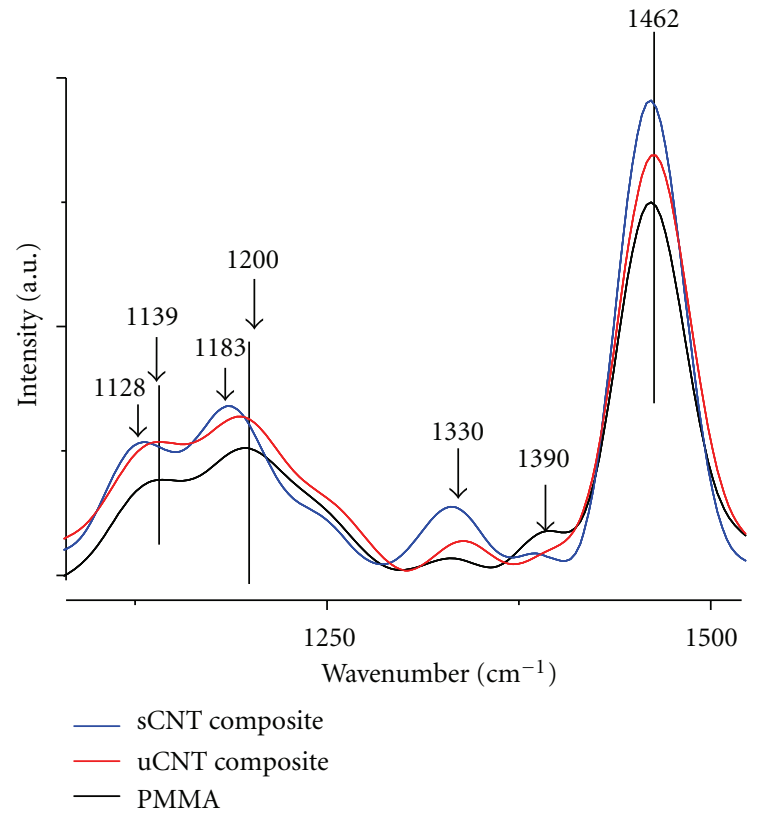

FIGURE 7: Raman spectra of PMMA and carbon nanotube polymer nanocomposites from $1080 \mathrm{~cm}^{-1}$ to $1500 \mathrm{~cm}^{-1}$.

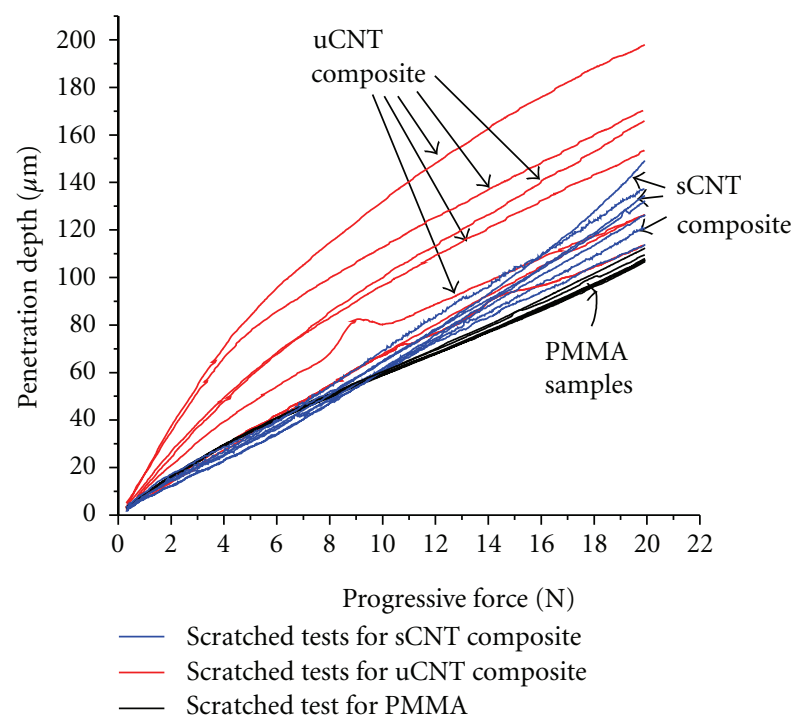

FIGURE 8: Microscratch testing results represented by penetration depth. Black line: Poly(methyl methacrylate) (PMMA), red line: $1 \mathrm{wt} \%$ unfunctionalized carbon nanotube polymer nanocomposite (uCNTs composite), blue line: $1 \mathrm{wt} \%$ functionalized silanized carbon nanotube polymer nanocomposite (uCNT composite).

Thus, neat PMMA has better scratch resistance than CNT's reinforced materials except for the composite with sCNTs at low forces. In addition, curves show that the behavior of the composite with sCNTs is more uniform than the composite with uCNTs. The fact related with the variety of curves, relatively far apart from each other, can be explained by formation of CNT bundles for uCNT composite. Thus, also in our systems, uniform distribution of CNTs in the matrix apparently achieved for sCNTs is important. It is supposed that good distribution of silanized carbon nanotubes (sCNTs) results in efficient tribological properties only at low loads as sCNTs could support the mechanical behavior. However, it is possible that the interaction produced between sCNTs and polymer chains could produce shorter chains than those produced in uCNT composites or PMMA. Thus, shorter chains at high loads could produce easy penetration in the material. As discussed by Dzenis [4], CNTs can produce improvement as well as worsening of the properties of matrices. This depends on diverse factors involved in the modification and synthesis of the nanocomposites.

3.6. General Discussion. Successful silanization of carbon nanotubes is useful for changing their surface behavior and, therefore, their dispersion in organic solvents. Substituents in the organosilane, here, play an important role.

When using 3-MAT, sCNT surfaces seem to have a variety of interactions with the PMMA matrix: $\mathrm{C}-\mathrm{C}, \mathrm{C}=\mathrm{C} \cdots \pi$, $\mathrm{C}=\mathrm{O} \cdots \mathrm{O}, \mathrm{C}=\mathrm{O} \cdots \mathrm{H}$ and $\mathrm{Si} \cdots \mathrm{H}$. The majority of these interactions begin in the polymerization.

The links produced in nanocomposites play an important role to improve thermomechanical properties in these materials, in as much as, storage modulus $\left(E^{\prime}\right)$ at different temperatures increase notably in the composites with sCNTs with respect to the composite with uCNTs and PMMA. In addition, the glass transition temperature is increased around $31^{\circ} \mathrm{C}$ in the composite with sCNTs with respect to polymer matrix, in comparison with uCNT system where $T_{g}$ only increase by $10^{\circ} \mathrm{C}$.

In other works moderate increments in mechanical properties have been achieved in PMMA matrix or copolymers using MMA when uCNTs have been incorporated, for instance with very low loads $(0.01 \mathrm{wt} \%)$ of SWMTs, and MWNTs have improved tensile modulus of polymer matrix [9], and storage modulus $E^{\prime}$ has been enhanced with $1 \mathrm{wt} \%$ of MWNTs using dissolving processing [13]. In addition other processing methods which involve uCNTs with other polymer matrices have reached good increments in storage modulus when uCNTs are aligned [9]. Nevertheless when CNTs are modified by oxidation [26], cover by polymers [27], or functionalized using other molecules [25, 27], better results have been reached in mechanical and thermal properties.

Recently, silanization have been an important route to modify CNTs, and the results agree with the thermomechanical properties reported here. Important increments in tensile strength in Poly(propylene) (PP) and polyimide (PI) matrices [40, 41] and and thermal stability in epoxy matrix [42] have been gotten at $1 \mathrm{wt} \%$ of sCNTs (PP and $\mathrm{PI}$ ) and $0.5 \mathrm{wt} \%$ (in the case of epoxy matrix). The silanes used in these researches were 3-methacryloxypropyltrimethoxysilane, vinyltriethoxysilane, and 3-Glycidoxypropyltrimethoxysilane, respectively. Also in recent times interesting dielectric properties have been reported in polyethylene reinforced with carbon nanofibers modified with silanes [43]. Thus, it is corroborated that silane functionalization in CNTs is useful to improve interface and thermomechanical 
properties in different polymer matrices including PMMA studied in this paper.

Also, functionalization effect is reflected in tribological properties; however, other factors such as the polymer chain sizes and the low concentration of sCNTs could influence the different behavior in tribological properties at low and high force. Nevertheless, the clear differences in the tribological behavior between $\mathrm{SCNT}$ and $\mathrm{uCNT}$ composites give evidence that silanization takes part in this property; the evidence of that influence is the low quantity used as reinforcement of sCNTs and the notable effect. The curves of penetration depth and progressive force are more consistent in the composite which contains more sCNTs than that in the composite with uCNTs. This allows concluding that functionalization, furthermore, assists the dispersion of carbon nanotubes in polymer composite.

Thus, this research gives evidence that the synergic effects produced in polymer composites are reached by interactions between organosilane chemical groups of modified nanotubes and polymer matrix. The incorporation of a small quantity of sCNTs is enough to produce significant changes at polymer matrix; even uCNTs provide considerable changes in polymer, taking into account the CNT quantity that is added; as well functionalization provides to the composites extra qualities, because of not only improving storage modulus and $T_{g}$, also uniform behavior is observed in any point of the sample when tribological properties are analyzed. These characteristics confer to this kind of nanocomposites' additional functional properties and the possibility to be incorporated in promising uses such as transportation industry, commercial aircraft, sports industry, and textile smart polymer fibers among others possible applications. Research using different concentrations of CNTs and other organosilanes with other R group related to the features of the polymer matrices is in current study.

\section{Acknowledgments}

The authors are grateful to Dr. G. Hernández-Padron for her assistance in the IR analysis and to CINVESTAV Querétaro, particularly Dr. S. Jimenez and Mr. F. Rodríguez for their assistance in Raman measurements. Financial support has been provided by the American Chemical Society, Washington, DC, the Mexican National Academy of Sciences (AMC), Mexico City, the DGEST under project DGEST 2006 333.06, and the Consejo Nacional de Ciencia y Tecnologia (CONAСyT), Mexico City under project JI-58232.

\section{References}

[1] M. Zhang, K. R. Atkinson, and R. H. Baughman, "Multifunctional carbon nanotube yarns by downsizing an ancient technology," Science, vol. 306, no. 5700, pp. 1358-1361, 2004.

[2] C. Velasco-Santos, A. L. Martinez-Hernandez, and V. M. Castano, "Carbon nanotube-polymer nanocomposites: the role of interfaces," Composite Interfaces, vol. 11, no. 8-9, pp. 567-586, 2005.
[3] C. Velasco-Santos, A. L. Martínez-Hernández, and V. M. Castaño, "Carbon nanotube-polymer nanocomposites: principles and applications," in Focus on Nanotube Research, D. A. Martin, Ed., vol. I, pp. 97-126, Nova Science Publishers, Huntington, NY, USA, 2006.

[4] Y. Dzenis, "Materials science: structural nanocomposites," Science, vol. 319, no. 5862, pp. 419-420, 2008.

[5] M. M. Treacy, T. W. Ebbesen, and J. M. Gibson, "Exceptionally high Young's modulus observed for individual carbon nanotubes," Nature, vol. 381, no. 6584, pp. 678-680, 1996.

[6] J. Hone, M. Whitney, C. Piskoti, and A. Zettl, "Thermal conductivity of single-walled carbon nanotubes," Physical Review B: Condensed Matter \& Materials Physics, vol. 59, no. 4, pp. R2514-R2516, 1999.

[7] T. W. Ebbesen, H. J. Lezec, H. Hiura, J. W. Bennett, H. F. Ghaemi, and T. Thio, "Electrical conductivity of individual carbon nanotubes," Nature, vol. 382, no. 6586, pp. 54-56, 1996.

[8] J.-P. Salvetat, J.-M. Bonard, N. H. Thomson et al., "Mechanical properties of carbon nanotubes," Applied Physics A: Materials Science and Processing, vol. 69, no. 3, pp. 255-260, 1999.

[9] C. A. Cooper, D. Ravich, D. Lips, J. Mayer, and H. D. Wagner, "Distribution and alignment of carbon nanotubes and nanofibrils in a polymer matrix," Composites Science and Technology, vol. 62, no. 7-8, pp. 1105-1112, 2002.

[10] C. Velasco-Santos, A. L. Martínez-Hernández, and V. M. Castaño, "Nanocomposites," in Proceedings of the NanoTech Conference Technical Proceedings (NSTI '05), vol. 2, p. 139, Anaheim, Calif, USA, 2005.

[11] L. Valentini, J. Biagiotti, J. M. Kenny, and M. A. López Manchado, "Physical and mechanical behavior of single-walled carbon nanotube/polypropylene/ethylene-propylenediene rubber nanocomposites," Journal of Applied Polymer Science, vol. 89, no. 10, pp. 2657-2663, 2003.

[12] H. Zhang and Z. Zhang, "Impact behaviour of polypropylene filled with multi-walled carbon nanotubes," European Polymer Journal, vol. 43, no. 8, pp. 3197-3207, 2007.

[13] C. Velasco-Santos, A. L. Martínez-Hernández, F. Fisher, R. S. Ruoff, and V. M. Castaño, "Dynamicalmechanical and thermal analysis of carbon nanotube-methylethyl methacrylate nanocomposites," Journal of Physics D: Applied Physics, vol. 36, no. 12, pp. 1423-1428, 2003.

[14] H. Xia and M. Song, "Preparation and characterization of polyurethane-carbon nanotube composites," Soft Matter, vol. 1, no. 5, pp. 386-394, 2005.

[15] Y.-K. Choi, Y. Gotoh, K. Sugimoto, S.-M. Song, T. Yanagisawa, and M. Endo, "Processing and characterization of epoxy nanocomposites reinforced by cup-stacked carbon nanotubes," Polymer, vol. 46, no. 25, pp. 11489-11498, 2005.

[16] L. F. Giraldo, W. Brostow, E. Devaux, B. L. López, and L. D. Pérez, "Scratch and wear resistance of polyamide 6 reinforced with multiwall carbon nanotubes," Journal of Nanoscience and Nanotechnology, vol. 8, no. 6, pp. 3173-3183, 2008.

[17] A. Allaoui, H. Bai, M. Cheng, and J. B. Bai, "Mechanical and electrical properties of a MWNT/epoxy composite," Composites Science and Technology, vol. 62, no. 15, pp. 1993-1998, 2002.

[18] J. Sandler, M. S. P. Shaffer, T. Prasse, W. Bauhofer, K. Schulte, and A. H. Windle, "Development of a dispersion process for carbon nanotubes in an epoxy matrix and the resulting electrical properties," Polymer, vol. 40, no. 21, pp. 5967-5971, 1999.

[19] J. K. W. Sandler, J. E. Kirk, I. A. Kinloch, M. S. P. Shaffer, and A. H. Windle, "Ultra-low electrical percolation threshold in 
carbon-nanotube-epoxy composites," Polymer, vol. 44, no. 19, pp. 5893-5899, 2003.

[20] Y. J. Kim, T. S. Shin, H. D. Choi, J. H. Kwon, Y.-C. Chung, and H. G. Yoon, "Electrical conductivity of chemically modified multiwalled carbon nanotube/epoxy composites," Carbon, vol. 43, no. 1, pp. 23-30, 2005.

[21] J. Suhr, N. Koratkar, P. Keblinski, and P. Ajayan, "Viscoelasticity in carbon nanotube composites," Nature Materials, vol. 4, no. 2, pp. 134-137, 2005.

[22] J. W. Cho, J. W. Kim, Y. C. Jung, and N. S. Goo, "Electroactive shape-memory polyurethane composites incorporating carbon nanotubes," Macromolecular Rapid Communications, vol. 26, no. 5, pp. 412-416, 2005.

[23] J. D. W. Madden, N. A. Vandesteeg, P. A. Anquetil et al., "Artificial muscle technology: physical principles and naval prospects," IEEE Journal of Oceanic Engineering, vol. 29, no. 3, pp. 706-728, 2004.

[24] W. Brostow, J-.L. Deborde, M. Jaklewicz, and P. Olszynski, "Tribology with emphasis on polymers: friction,scratch resistance and wear," Journal of Materials Education, vol. 25, pp. 119-126, 2003.

[25] M. C. Paiva, B. Zhou, K. A. S. Fernando et al., "Physical and mechanical characterization of nanocomposites with carbon nanotubes functionalized with the matrix polymer," Composite Interfaces, vol. 12, no. 8-9, pp. 757-768, 2005.

[26] C. Velasco-Santos, A. L. Martínez-Hernández, F. T. Fisher, R. Ruoff, and V. M. Castaño, "Improvement of thermal and mechanical properties of carbon nanotube composites through chemical functionalization," Chemistry of Materials, vol. 15, no. 23, pp. 4470-4475, 2003.

[27] M. Wang, K. P. Pramoda, and S. H. Goh, "Enhancement of the mechanical properties of poly(styrene-co-acrylonitrile) with poly(methyl methacrylate)-grafted multiwalled carbon nanotubes," Polymer, vol. 46, no. 25, pp. 11510-11516, 2005.

[28] C. Velasco-Santos, A. L. Martínez-Hernández, M. LozadaCassou, A. Alvarez-Castillo, and V. M. Castaño, "Chemical functionalization of carbon nanotubes through an organosilane," Nanotechnology, vol. 13, no. 4, pp. 495-498, 2002.

[29] J. Kastner, T. Pichler, H. Kuzmany et al., "Resonance Raman and infrared spectroscopy of carbon nanotubes," Chemical Physics Letters, vol. 221, no. 1-2, pp. 53-58, 1994.

[30] J. Coates, "Interpretation of infrared spectra, a practical approach," in Encyclopedia of Analytical Chemistry, R. A. Meyers, Ed., pp. 10815-10837, John Wiley \& Sons, Chichester, UK, 2000.

[31] J. Zhang, H. Zou, Q. Qing et al., "Effect of chemical oxidation on the structure of single-walled carbon nanotubes," Journal of Physical Chemistry B, vol. 107, no. 16, pp. 3712-3718, 2003.

[32] J. Chen, A. M. Rao, S. Lyuksyutov et al., "Dissolution of fulllength single-walled carbon nanotubes," Journal of Physical Chemistry B, vol. 105, no. 13, pp. 2525-2528, 2001.

[33] P. C. Ma, J.-K. Kim, and B. Z. Tang, "Functionalization of carbon nanotubes using a silane coupling agent," Carbon, vol. 44, no. 15, pp. 3232-3238, 2006.

[34] E. Bourgeat-Lami, I. Tissot, and F. Lefebvre, "Synthesis and characterization of $\mathrm{SiOH}$-functionalized polymer latexes using methacryloxy propyl trimethoxysilane in emulsion polymerization," Macromolecules, vol. 35, no. 16, pp. 6185-6191, 2002.

[35] E. F. Lucas, B. G. Soares, and E. Monteiro, Caracterizaçao de Polimeros, Determinação de peso Molecular e Análise Térmica, E-Papers, Rio de Janeiro, Brazil, 2001.

[36] A. L. Martinez-Hernandez, C. Velasco-Santos, M. de Lcaza, and V. M. Castaño, "Grafting of methyl methacrylate onto natural keratin,” e-Polymers, no. 016, pp. 1-11, 2003.
[37] A. Matsushita, Y. Ren, K. Matsukawa et al., "Two-dimensional Fourier-transform Raman and near-infrared correlation spectroscopy studies of poly(methyl methacrylate) blends. 1 . Immiscible blends of poly(methyl methacrylate) and atactic polystyrene," Vibrational Spectroscopy, vol. 24, no. 2, pp. 171$180,2000$.

[38] D. Baskaran, J. W. Mays, and M. S. Bratcher, "Noncovalent and nonspecific molecular interactions of polymers with multiwalled carbon nanotubes," Chemistry of Materials, vol. 17, no. 13, pp. 3389-3397, 2005.

[39] R. W. Hannah and D. W. Mayo, "Introduction in courses notes in the interpretation of infrared and raman spectra," in Infrared Spectra of Polymers, D. Mayo, F. Miller, and R. Hannah, Eds., p. 261, John Wiley \& Sons, Chichester, UK, 2003.

[40] Z. Zhou, S. Wang, L. Lu, Y. Zhang, and Y. Zhang, "Functionalization of multi-wall carbon nanotubes with silane and its reinforcement on polypropylene composites," Composites Science and Technology, vol. 68, no. 7-8, pp. 1727-1733, 2008.

[41] S.-M. Yuen, C.-C. M. Ma, C. L. Chiang, C.-C. Teng, and Y.-H. $\mathrm{Yu}$, "Poly(vinyltriethoxysilane) modified MWCNT/polyimide nanocomposites-preparation, morphological, mechanical, and electrical properties," Journal of Polymer Science, Part A, vol. 46, no. 3, pp. 803-816, 2008.

[42] P. Cheng, J.-K. Kim, and B.-Z. Tang, "Effects of silane functionalization on the properties of carbon nanotube/epoxy nanocomposites," Composites Science and Technology, vol. 67, no. 14, pp. 2965-2972, 2007.

[43] T. Liu, W. Wood, and W.-H. Zhong, "Sensitivity of Dielectric Properties to Wear Process on Carbon Nanofiber/HighDensity Polyethylene Composites," Nanoscale Research Letters, vol. 6, no. 1, pp. 1-9, 2011. 

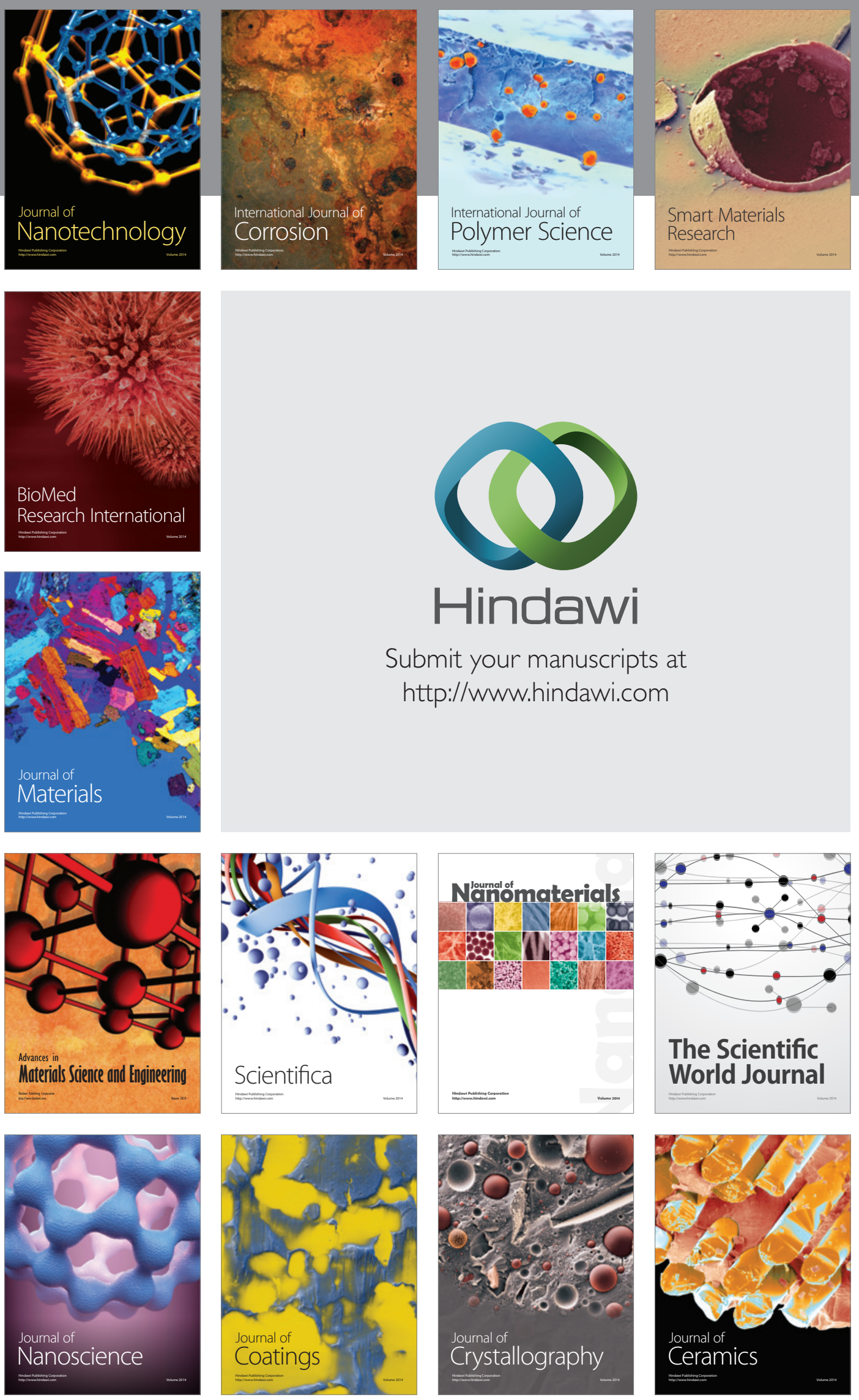

The Scientific World Journal

Submit your manuscripts at

http://www.hindawi.com

\section{World Journal}

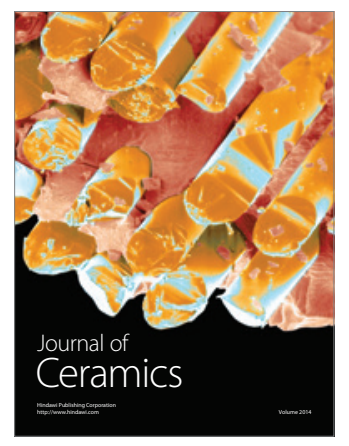

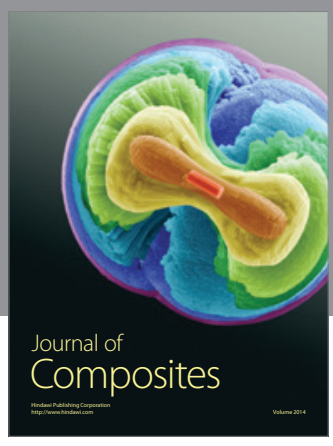
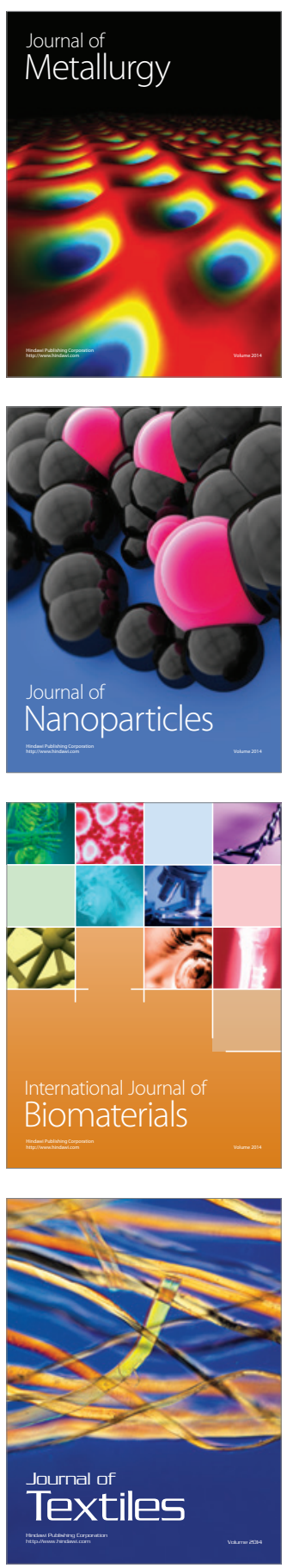